\title{
A ATIVIDADE ECONÔMICA E POLITICA DA PLEBE URBANA NA ROMA IMPERIAL
}

\author{
Ludmilla Savry dos Santos Almeida
}

Universidade de São Paulo

Resumo: As populaçóes urbanas das grandes cidades antigas, principalmente Atenas $\theta$ Roma, têm sido tratadas como sendo compostas, em sua maior parte, por uma massa ociosa que vivia às expensas do trabalho escravo. Estudos mais recentes têm demonstrado, entretanto, que tal formulação não corresponde às evidéncias. Em Roma, a distribuição de viveres não garantiu, em momento algum, o sustento individual. Em face desta constatação, a necessidade de que parte significativa da plebe urbana teria que ser produtiva se impóe.

0 conceito de ociosidade económica se ligaria ao de passividade política, sobretudo no Império. Sem a participação direta, característica da República, a população da cidade de Roma teria sofrido um processo de despolitização. 0 "pão e circo" seriam oferecidos, então, em troca de uma configuração política livre de questionamentos.

Pretendemos, através das fontes do período, demonstrar nossa argumentação contrária aos conceitos, paralelos em nosso entender, de ociosidade económica e de neutralidade política da população urbana de Roma durante o Império.

Palavras-chave: História Romana, Império, plebe urbana de Roma, participação política e económica.

A questão da plebe urbana concentrada em grandes cidades, como Roma e Atenas, tem sido alvo de diferentes estudos centralizados, sobretudo, no aspecto sócio-econônico.

Ludwig Friedlaender (Friedlaender, 1890, p. 248) afirma que predominava em Roma uma massa perigosa de despossuidos e corrompidos, em seu entender pior que a existente nas metrópoles da segunda metade do século XIX. Bem antes dele Charles Montesquieu, em "0 Espirito das Leis", destaca a existência na Antigüidade de um desprezo pelo trabalho industrial e agrícola. A partir de consideraçōes como estas, surgiu toda uma corrente que defendeu a configuração de um sistema econômico produtivo baseado majoritariamente na utilização de trabalho escravo. Tal fato levaria a um desdobramente politico pois, desta forma, 0 escravismo seria condição essencial e indispensável ao aparecimento dos sistemas políticos característicos do período. Eles teriam como base um corpo de cidadãos alheios ao trabalho, diferenciados em ricos e pobres, embos vivendo às expensas da mão de obra escrava. A interpretação do papel da coletividade escrava tendeu a ser engrandecida pela visão estereotipada da população ociosa.

E. M. Wood (Wood, 1988, p.08) cita Adam Ferguson, alertando que, no caso de Atenas, a riqueza era mal distribuída, estando somente os ricos isentos do 
trabalho, enquanto que os demais tinham necessariamente que exercer uma atividade produtiva para garantir sua subsistência.

Em análises recentes, podemos constatar que o papel do trabalho escravo, sobretudo nas atividades urbanas, foi super valorizado e a avaliação do real desempenho dos cidadăos livres produtivos, mal calculada. Através de uma inscrição do século III (C. I. L., VI, 1785), podemos observar o Imperador Aureliano conferindo aos operários, que trabalhavam na construção da muralha de Roma, a honraria de serem designados coletivamente como "operarii Antonii". Fossem eles escravos, não teriam recebido tal distinção.

Sabemos que a economia era baseada na predominância do setor agrícola. Contudo, a maciça utilização da mão de obra escrava no campo, não deve ser simplesmente transferida para 0 quadro urbano nas mesmas proporçōes. Se 0 peso do trabalho escravo tem sido reavaliado na agricultura, tal medida se mostra ainda mais necessária no que se refere às atividades eminentemente urbanas. Dentro do campo de análise marxista, 0 "mito" da população ociosa permaneceu de forma marcante na concepção do modo de produção escravista. Todavia, a teoria manxista admite interpretaçōes diferentes da convencional, que afirma ser a base produtiva constitulda por escravos, no sentido de que eram eles os realizadores da maior parte do trabalho produtivo. Um dos exemplos mais claros desta reavaliação é a obra "Class struggle in the ancient Greek world" de Saint-Croix, na qual é defendida a premissa de que os pequenos produtores livres $e$ independentes eram responsáveis por parte substancial, talvez majoritária da produção tanto em Atenas como em Roma. Para este autor, 0 conceito de modo de produção escravista deve ser utilizado, não porque os escravos constituissem o elemento produtivo principal, mas por ser o escravismo a forma principal através da qual a mais-valia era extraída pelas classes dominantes e proprietárias.

Além desta revisão geral do papel desempenhado no setor produtivo por escravos e cidadãos livres, faz-se necessária, também, uma análise do próprio conceito de plebe. A plebe urbana da capital do Império era parte integrante de uma plebe romana que inclúa igualmente a plebe rústica e as existentes nas províncias. 0 segmento urbano era formado por diferentes subgrupos. Em comum entre eles, só o fato de não pertencerem nem à ordem eqūestre nem à senatorial. Em termos práticos, eram os cidadāos livres, com renda inferior a quatrocentos mil sestércios. Deste modo, um pequeno comerciante, um liberto que se tornara professor de retórica e um pedinte faziam todos, sem distinção, parte da mesma plebe urbana. Admite-se que o número de escravos libertos dentro deste grupamento era considerável, porém apenas poucos elementos se tornaram ricos. Alguns permaneceram ligados economicamente aos seus antigos proprietários, outros se tornaram independentes, chegando a ocupar cargos importantes dentro da burocracia imperial. Assim, não havia um padrăo marcado ou uma unidade de atitudes ou de pensamento que pudesse ser qualificada como característica do grupo plebe. Como jamais a plebe urbana de Roma se constituiu numa ordem, em razão de sua própria heterogeneidade, um estudo como o realizado por Claude Nicolet em "L'ordre equestre à époque républicaine" se mostra uma tarefa extremamente árdua, até hoje, dentro da historiografia. Diante da diversidade existente, a maioria dos especialistas preferiu focalizar alguns aspectos e hábitos, a tratar de uma história geral da plebe. 
0 estereótipo da plebe ociosa teve em parte como embasamento a leitura de fontes como Frontino e Juvenal. Este último (Juvenal - X, 80-81) afirma que a plebe urbana de Roma só se preocupava com a distribuição de alimentos e com os espetáculos públicos, mostrando-se indiferente aos demais acontecimentos. É preciso analisar tal tipo de consideração e confrontá-la com as evidências de outras fontes. Para que a plebe urbana fosse ociosa, era preciso que o Estado the fornecesse 0 sustento básico para sua sobrevivência. Sabemos que o fornecimento e 0 abastecimento regular e organizado de viveres era um dos elementos-chave no bom relacionamento do Príncipe com a população da capital do Império: Contudo, tal distribuiçăo de produtos atingia somente a uma minoria. Jean Le Gall (Le Gall, 1971 , p. 267) conclui que a quantidade de gêneros oferecidas em doações, bastante irregulares, era mais do que o necessário para a manutenção de uma pessoa, porém não o suficiente para duas, do ponto de vista quantitativo. Quanto à variedade, encontramos nas fontes - sobretudo do século III - (Aurélio Vitor - XXXV, 7), referências à distribuiç̧ão, pelo Imperador, de gêneros básicos como azeite e carnes, mas tal prática não foi uma constante. Outro modo pelo qual alguns membros da plebe poderiam conseguir produtos era a espórtula. Seu significado original era o da pequena cesta que os ricos ofereciam aos seus clientes com sobras do banquete da véspera, acrescida de algumas moedas. Por vezes, ela se apresentava como uma pequena quantia em dinheiro, irregularmente doada por particulares. Seu alcance, todavia, ainda foi mais restrito do que a distribuição oficial do Estado.

Zvi Yavetz (Yavetz, 1987, p. 181) cita Dião da Prusa, contradizendo Juvenal, ao alertar que para sobreviver em Roma, ninguém poderia permanecer na ociosidade todo o tempo, pois a vida na cidade era dispendiosa, com produtos $\mathrm{e}$ aluguéis caros. Se o sustento da plebe urbana de Roma não estava garantido pelos mecanismos de distribuição gratuita, podemos concluir que havia a necessidade de que parte significativa de seus membros exercesse um trabalho produtivo, garantindo sua subsistência básica, fosse pessoal, ou familiar. Em face de todas estas constataçōes, não podemos deixar de questionar a utilização do "mito" da população ociosa dentro da produção historiográfica referente, sobretudo, ao período do Alto-Império.

Paralelamente à fiç̧ão de uma ociosidade econômica encontramos uma outra a ela relacionada: a de uma neutralidade política da plebe urbana de Roma. Sem a participação clvica do cidadão, característica da República, através de voto nas assembléias, a população de Roma tería sofrido um processo acentuado de despolitização. A idéia central deste tipo de abordagem seria a troca realizada pela plebe de passividade politica por comida e lazer. Em sua obra principal acerca do tema, Paul Veyne (Veyne, 1976) nega 0 argumento da despolitização, introduzindo 0 conceito de "evergetismo" - noção atemporal que atuaria como um mecanismo de regulagem social. Julgamaos que a maior lacuna da abordagem realizada pelo autor seja a análise de modo unilateral do ato de conceder e custear alimentação e divertimento. Somente sã̃o discutidas as razōes de quem faz as doações. 0 outro lado do processo, ou seja, a plebe urbana de Roma que as recebe, não é tratado.

Nossa crítica ao conceito de despolitização baseia-se na análise de diversas fontes do periodo imperial que demonstram, em várias passagens, manifestaçōes da plebe urbana de Roma, inclusive de cunho politico, em circos e anfiteatros. Como exemplo, Herodiano (Herodiano - I - 12,5) mostra que os romanos organizaram manifestaçōes no teatro contra Cleandro, colaborador de 
Cômodo, porque 0 consideravam responsável pela carestia e pela peste reinantes no período. 0 mesmo autor (Herodiano - $\|-7,3$ ) narra que a multidão, reunida no circo, insultou Dídio Juliano e aclamou Pêscenio Niger como defensor do Império. Tácito (Tácito - VI, 13), por sua vez, cita uma grave crise que quase levou à sedição causada pela carestia de viveres. Durante 0 ocorrido, travaram-se no circo fortes discussões, menos respeitosas que de costume, contra Tibério. Augusto, segundo Amiano Marcelino (Amiano Marcelino - XVI, 10,13), se divertia com a ousadia dos espectadores que sabiam evitar a insolência, sem abandonar sua antiga liberdade.

Em nosso entender, os espetáculos oficiais eram muito mais do que um simples mecanismo de despolitização. Eles se apresentavam como uma das poucas oportunidades que tinha a população urbana de expressar suas aspirações diante das autoridades presentes, frequentemente perante o próprio Imperador. Não haveria assim uma politica consciente de despolitização das massas, mesmo 0 Príncipe não necessitando de apoio popular em eleições. Segundo Zvi Yavetz (Yavetz, 1987, p. 171), interessava-Ihe, sem dúvida, a colaboração da plebe de Roma como último recurso contra senadores hostis ou pretorianos rebeldes. Consideramos que, apesar da fraqueza política, a plebe urbana não era um fator inteiramente desprezivel dentro da política imperial.

Diante do exposto, podemos observar que os esterétipos de passividade política e de ociosidade econômica são interligados como parte integrante de um mesmo tipo de argumentação. Tais conceitos procurariam demonstrar que a plebe urbana de Roma era um grupo de ociosos embrutecidos que não exerceria nenhuma atividade produtiva. Eles seriam mantidos pelo Estado e estariam completamente alijados do sistema político. Nossa argumentação, contrária a estas noções, encontra subsidios nas fontes consultadas e em parte da historiografia contemporânea. Não podemos mais aceitar, sem o devido questionamento, tais proposições. É certo que existiam vagabundos e mendigos, vivendo sem exercer uma ativdade produtiva fixa e não possuíndo, nas palavras de Marcial (Marcial - XI, 32), "nem toga, nem cama, nem tijela ou escravo". Porém jamais foram eles a maioria da plebe urbana de Roma. A população da cidade também não se encontrava totalmente alheia ao processo político existindo manifestações $e$ reivindicações que demonstram algo mais do que simples passividade ou alienação coletiva. Vimos alguns casos concretos desta movimentação, ocorridos em circos e anfiteatros. É precisamente a plebe urbana de Roma diversificada, mas atuante politica e economicamente, que precisa ser resgatada para a melhor compreensão do seu papel dentro da formação social romana do Império.

\section{Bibloggrafia}

AMMIEN MARCELIN. Histoire. Texte établi et traduit par Jacques Fontaine. Paris: Les Belles Lettres. 1987. 2v.

AURÉluS VICTOR. Livre des Césars. Traduction nouvelle par Pierre Dufraigne. Paris: Les Belles Lettres. 1975.

CORPUS INSCRIPTIONUM LATINARUM (C. I. L.). Consilio et auctoritate Academie litterarum Borussicae editum. Berlin: Academie Verlag, 1869. v. 6. 
ERODIANO. Storia dell' Impero Romano dopo Marco Aurelio. Traduzione Fabrizio Conco. Firenze: Sansoni, 1967.

FRIEDLAENDER, L. Les jeux In: MARQUARDT, $\mathrm{K}$. org. Le culte chez les romains. Paris: Thorin, 1890. p. 247-349.

FRIEDLAENDER, L. Moeurs romaines d' Auguste a la fin du siècle des Antonins. Paris: C. Reinwald, 1867.

JUVENAL. Satyres. Texte établi et traduction par Piere Labriolle et François Villeneuve. Paris: Les Belles Lettres, 1921.

LE GALL. J. Rome, ville de fainéants? revue des Etudes Latines. Paris, 44, p. 266$277,1971$.

MARTIAL. Épigrammes. Texte établi et traduit par H. J. Izaac. Paris: Les Belles Lettres, 1962. 2v.

PATLAgean. E. Aspetti politici della povertà urbana in: PATLAgean. E. Povertà ed emarginazione a Bisanzio. Bari: Laterza, 1986. p. 93-126.

RUDE. G. A multidão na História. Tradução por Waltensir Dutra. Rio de Janeiro: Campus, 1991.

TACITE. Annales. Texte ètabli et traduit par Pierre Wuillenier. Paris: Les Belles Lettres, 1978. 3v.

VEYNE. P. Le pain et le cirque. Sociologie historique d'un pluralisme politique. Paris: Seuil, 1976.

VEYNE. P. Panen et circenses: 1 'évergétisme devant les sciences humaines. Annales ESC. Paris, ne 3, p. 785-825, 1966.

WOOD. E. M. The myth of the idle mob In: W00D. E. M. Peasant - Citzen and slave. London: Verso, 1988. p. 5-4l.

YAVETZ. Z. Plebs and Princeps. Oxford: University Press, 1969.

YAVETZ. Z. The Urban plebs in the Flavians, Nerva and Trajan In: Entretiens sur 1 Antiquité classique - Oppositions et résistances à 1'Empire d'Auguste à Trajan. Genève: Fondation Hardt. 1987, t. 33, p. 135-186. 